\title{
Antibiotic utilization in hospitalized children under 2 years of age with influenza or respiratory syncytial virus infection - a comparative, retrospective analysis
}

Cihan Papan ${ }^{1,2^{*}} \mathbb{D}$, Meike Willersinn ${ }^{1}$, Christel Weiß ${ }^{3}$, Michael Karremann ${ }^{1}$, Horst Schroten ${ }^{1}$ and Tobias Tenenbaum ${ }^{1}$

\begin{abstract}
Background: Infections due to Respiratory Syncytial Virus (RSV) and Influenza virus (FLU) are leading causes of hospitalization in young children. Yet, there is little data on factors associated with antibiotic use in these patients.

Methods: We conducted a retrospective, single-center study of all patients below 2 years of age hospitalized between 2014 and 2018. We compared children with RSV infection to children with FLU infection analyzing clinical characteristics and factors contributing to an increased rate of antimicrobial utilization.

Results: RSV infection was diagnosed in 476/573 (83.1\%), FLU in 95/573 (16.6\%), and RSV-FLU-co-infection in 2/573 (0.3\%) patients. Median age was lower for RSV compared to FLU (4 vs. 12 months; $p<0.0001$ ). Children with RSV had longer hospitalization ( 5 vs. 4 days; $p=0.0023)$ and needed oxygen more frequently $(314 / 476$ vs. 23/95; $p<$ $0.0001)$ than FLU patients. There was no significant difference in the overall antibiotic utilization between RSV and FLU patients (136/476 vs. 21/95; $p=0.2107)$. Logistic regression analyses revealed that septic appearance on admission (odds ratio [OR] 8.95, 95\% confidence interval [Cl] 1.5-54.1), acute otitis media (OR 4.5, 95\% Cl 2.1-9.4), a longer oxygen therapy (OR 1.40; 95\% Cl 1.13-1.74) and a higher C-reactive protein (CRP) (OR 1.7, 95\% Cl 1.5-2.0) were significantly associated with antibiotic use in both groups, but not age or pneumonia.
\end{abstract}

Conclusions: In our cohort, the rate of antibiotic utilization was comparable between RSV and FLU patients, while for both groups distinct clinical presentation and a high CRP value were associated with higher antibiotic use.

Keywords: Influenza virus, Respiratory syncytial virus, Infants, Children, Antimicrobial stewardship

\footnotetext{
* Correspondence: cihan.papan@uks.eu

${ }^{1}$ Pediatric Infectious Diseases, Medical Faculty Mannheim, Heidelberg

University, Mannheim, Germany

${ }^{2}$ Center for Infectious Diseases, Institute of Medical Microbiology and

Hygiene, Saarland University, Kirrberger Strasse, Building 43, 66421 Homburg, Germany

Full list of author information is available at the end of the article
}

(c) The Author(s). 2020 Open Access This article is licensed under a Creative Commons Attribution 4.0 International License, which permits use, sharing, adaptation, distribution and reproduction in any medium or format, as long as you give appropriate credit to the original author(s) and the source, provide a link to the Creative Commons licence, and indicate if changes were made. The images or other third party material in this article are included in the article's Creative Commons licence, unless indicated otherwise in a credit line to the material. If material is not included in the article's Creative Commons licence and your intended use is not permitted by statutory regulation or exceeds the permitted use, you will need to obtain permission directly from the copyright holder. To view a copy of this licence, visit http://creativecommons.org/licenses/by/4.0/ The Creative Commons Public Domain Dedication waiver (http://creativecommons.org/publicdomain/zero/1.0/) applies to the data made available in this article, unless otherwise stated in a credit line to the data. 


\section{Background}

Respiratory tract infections (RTI) are the most common diagnoses in children, especially below the age of 2 years [1]. They substantially contribute to morbidity and mortality worldwide [2]. Furthermore, RTI are associated with large societal impacts [3], including a high healtheconomic burden [4], caused by a high hospitalization rate among the very young, causing frequent parental absence from work [5]. Moreover, antimicrobial consumption is heavily driven by RTI [6] due to the clinical challenge of distinguishing between viral and bacterial etiologies and the lack of a reliable diagnostic reference standard [7, 8]. Antimicrobial stewardship (AMS) programs are increasingly implemented [9] to counteract this antibiotic overuse which is strongly associated with the upsurge in antimicrobial resistance [10],

The respiratory syncytial virus (RSV) and the Influenza virus (FLU) account for the majority of RTI in infants leading to hospitalization $[11,12]$. With the advent of novel point-of-care tests based on nucleic acid amplification, diagnostic accuracy and turnaround time of results have dramatically increased over the past years, both for RSV and FLU $[13,14]$. Yet, there is only limited data indicating the potential clinical benefit of rapid viral testing as a tool of AMS in the hospital setting [15]. The overall quality of evidence was generally regarded low, making only for a "weak recommendation" in the latest Guidelines by the Infectious Diseases Society of America and the Society for Healthcare Epidemiology of America for implementing an AMS program [16].

In a recent systematic review with meta-analysis, including both diagnostic accuracy studies and clinical impact studies, no firm conclusion could be made on the clinical impact of viral testing on antibiotic use due to the heterogeneity of the included studies [17], of which only two had included children.

Little is known about the factors that influence antibiotic prescription in patients with a positive RSV or FLU test. We sought to analyze the rate of antibiotic use in RSV and FLU patients and associated clinical and laboratory factors.

\section{Methods}

\section{Study setting and design}

This retrospective, single-center analysis was conducted at the University Children's Hospital Mannheim, Medical Faculty Mannheim of the Heidelberg University, Germany. The local ethics committee approved of the study (2018-832R-MA). All patients below 2 years of age hospitalized for RSV or FLU infection between the April 2014 and April 2018 were included, thereby covering 4 complete epidemic seasons. Patients were identified by a hospital database search for the corresponding ICD-10 codes (J12.1, J21.0, J20.5, B97.4; J09-J11.-) as the primary diagnosis and, to avoid selection bias, also as secondary diagnosis. RSV or FLU infection were each defined as a positive result from a nasopharyngeal swab either in a rapid point-of-care test (Sofia ${ }^{\circ}$ Influenza A + B Fluorescent Immunoassay and Sofia ${ }^{\bullet}$ RSV Fluorescent Immunoassay; Quidel, San Diego, California, USA) or in a multiplex PCR (Biofire $^{\circledast}$ Filmarray ${ }^{\oplus}$ Respiratory Panel, Biomérieux, Marcyl'Étoile, France), which comprises adenovirus; coronaviruses 229E, HKU1, OC43, and NL63; human metapneumovirus; human rhinovirus/enterovirus; influenza A (including substrains) and B; parainfluenza viruses 1 to 4; RSV; Bordetella pertussis; Chlamydophila pneumoniae; and Mycoplasma pneumoniae.

Chart review included present and past medical history, family history, preexisting antibiotic therapy, clinical findings, results of laboratory, microbiological and radiological investigations, data on therapy, need for oxygen, intensive care, and length of stay. Clinical appearance was defined as documented as the physical examination upon admission, including "well", "ill", and "septic" appearance. The clinical syndrome was defined according to the discharge diagnosis and/or the documented clinical symptoms on admission, as either upper respiratory tract infection (URTI), bronchitis/bronchiolitis, pneumonia, or fever of unknown origin (FUO).

Case numbers were compared between the seasons to check for imbalances.

We compared children with RSV infection to children with FLU infection. Especially, clinical characteristics and factors contributing to an increased rate of antimicrobial utilization were analysed of RSV and FLU infected children. Furthermore, we defined subgroups of children within each group and compared those treated with antibiotics (RSV+AB+; FLU $+A B+)$ to those who were not treated with antibiotics (RSV+AB-; FLU $+A B-)$, respectively. Antibiotic utilization was defined as any given dose during the hospital stay. We assessed antibiotic therapy in terms of substance and length of therapy.

\section{Statistical analysis}

Statistical analyses were performed in SAS (Statistical Analysis System, North Carolina, USA). Mann-Whitney U test was used for group comparison between RSV and FLU. For multiple comparisons, Kruskal-Wallis test and one-way analysis of variance were applied. Logistic regressions were performed to assess potential risk factors for antibiotic utilization.

\section{Results}

\section{Demographic data}

Overall, 573 children were eligible for analysis, with a median age of 5 months (IQR 2-11) and a male predominance of $325 / 573$ (56.7\%). Of the 573 children, 476 were identified as having RSV infection (83.1\%), and 95 as 
having FLU infection (16.6\%), while in two patients, RSVFLU co-infection was detected (0.3\%). RSV patients were significantly younger than FLU patients (4 vs. 12 months; $p<0.0001$ ) (Table 1), while $19.5 \%$ of RSV patients were 28 days of age or younger and $47.7 \% 3$ months of age or younger. The majority of RSV patients presented during the months January and February (32.4 and 25.4\%), while FLU patients were predominantly diagnosed in February and March (43.2 and 25.3\%) (Fig. 1).

\section{Seasonality}

We assessed the seasonal variability (Fig. 1). Numbers were comparable between the seasons except for one season each with a higher burden of RSV (2016/2017) and FLU (2017/2018).

\section{Baseline risk factors}

We assessed patients with respect to a positive past medical history with focus on prematurity, congenital heart disease, congenital diaphragmatic hernia, trisomy 21 , and recurrent episodes of bronchitis, but could not find any significant differences, although prematurity and recurrent bronchitis were slightly more common in RSV (4.4 and 4.8\%, respectively) than in FLU patients (2.1 and $3.1 \%$, respectively), both missing statistical significance. Furthermore, similar sick contacts were

Table 1 Comparison of clincial and laboratory characteristics of RSV and FLU patients; median and interquartile range are indicated for continuous variables; ns not significant

\begin{tabular}{|c|c|c|c|}
\hline Variables & RSV & FLU & $p$-values \\
\hline N (\%) & $476(83.1 \%)$ & $95(16.6 \%)$ & \\
\hline Male & 269/476 (56.5\%) & 55/95 (57.9\%) & ns \\
\hline Age, months & $4(2-8)$ & $12(5.5-18)$ & $<0.0001$ \\
\hline Duration of illness, days & $4(2-5)$ & $3(2-5)$ & 0.0005 \\
\hline Fever $\left(\geq 38.0^{\circ} \mathrm{C}\right)$ & $330 / 476(69.3 \%)$ & 93/95 (97.9\%) & $<0.0001$ \\
\hline Body temperature on admission, ${ }^{\circ} \mathrm{C}$ & $37.5(37.1-38.3)$ & $38.4(37.5-39.3)$ & $<0.0001$ \\
\hline Peak body temperature, ${ }^{\circ} \mathrm{C}$ & $38.7(37.7-39.4)$ & $39.9(39.1-40.1)$ & $<0.0001$ \\
\hline Oxygen saturation at admission, \% & 97 (94-98) & $98(96-100)$ & 0.0002 \\
\hline Minimal oxygen saturation, \% & $90(88-94)$ & $96(90-98)$ & $<0.0001$ \\
\hline Need for intensive care & $16 / 476(3.4 \%)$ & $1 / 95(1.1 \%)$ & ns \\
\hline Length of stay, days & $5(4-7)$ & $4(3-6.5)$ & 0.0023 \\
\hline Blood culture obtained & $165 / 476(34.7 \%)$ & $54 / 95(56.8 \%)$ & $<0.0001$ \\
\hline CRP on admission, mg/L & $6.9(0-17.6)$ & $6.6(0-14.1)$ & ns \\
\hline Peak CRP, mg/L & $12.3(5.8-29.2)$ & $11.7(5.4-23.7)$ & ns \\
\hline WBC on admission, $10 \wedge 9 / \mathrm{L}$ & $10.7(8.5-13.2)$ & $10.8(7.1-13.6)$ & ns \\
\hline Chest radiography performed & $135 / 476(28.4 \%)$ & 18/95 (18.9\%) & ns \\
\hline Infiltrate on chest radiogram & $72 / 135$ (53.3\%) & 13/18 (72.2\%) & ns \\
\hline Preexisting antibiotic therapy & $32 / 476(6.7 \%)$ & 14/95 (14.7\%) & 0.0188 \\
\hline Well appearance & $32 / 476(6.7 \%)$ & 6/95 (6.3\%) & ns \\
\hline III appearance & $245 / 476(51.5 \%)$ & 62/95 (65.3\%) & 0.0176 \\
\hline Septic appearance & 168/476 (35.3\%) & 23/95 (24.2\%) & 0.0426 \\
\hline Febrile seizure & $3 / 476(0.6 \%)$ & 14/95 (14.7\%) & $<0.0001$ \\
\hline Acute otitis media & $70 / 476(14.7 \%)$ & 33/95 (34.7\%) & $<0.0001$ \\
\hline Upper respiratory tract infection & 0/476 (0\%) & 47/95 (49.5\%) & $<0.0001$ \\
\hline Bronchitis/Bronchiolitis & 236/476 (49.6\%) & 6/95 (6.3\%) & $<0.0001$ \\
\hline Pneumonia & 239/476 (50.2\%) & 21/95 (22.1\%) & $<0.0001$ \\
\hline Fever of unknown origin & $1 / 476(0.2 \%)$ & 21/95 (22.1\%) & $<0.0001$ \\
\hline Death & $0 / 476$ & $1 / 95(1.1 \%)$ & ns \\
\hline Oxygen therapy & $314 / 476(66.0 \%)$ & 23/95 (24.2\%) & $<0.0001$ \\
\hline Length of oxygen therapy, days & $2(0-5)$ & 0 & $<0.0001$ \\
\hline Antibiotic therapy & $136 / 476(28.6 \%)$ & $21 / 95(22.1 \%)$ & 0.2107 \\
\hline
\end{tabular}




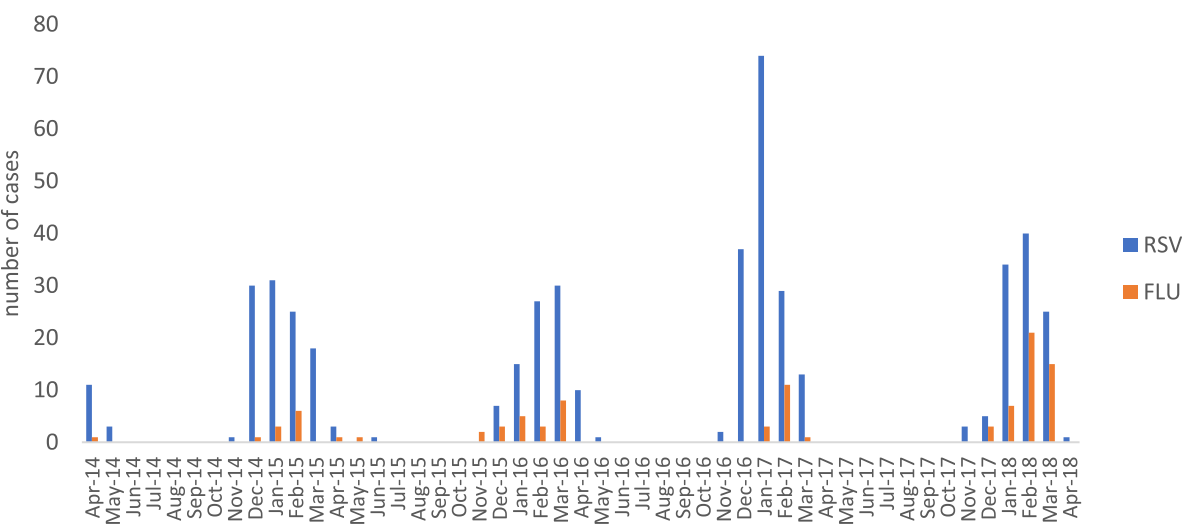

Fig. 1 Distribution of cases for each month for RSV (blue) and FLU (orange)

observed for $38.9 \%$ of RSV and for $45.3 \%$ of FLU patients (statistically not significant).

\section{Clinical presentation, treatment and outcome of RSV and FLU patients}

Both patient groups presented with similar durations of illness, but a significant number of FLU patients had received antibiotics before presenting to the hospital $(14.7 \%$ vs. $6.7 \% ; p=0.0188)$. The clinical syndrome diagnosed upon admission was lower respiratory tract infection (49.6\%) or pneumonia (50.2\%) for most of the RSV patients (compared to $6.3 \%$ und $22.1 \%$ for FLU patients, respectively; both $p<0.0001$ ), while in FLU patients, upper respiratory tract infections $(49.5 \%)$ and FUO (22.1\%) accounted for the majority of clinical manifestations (compared to 0.2 and $0 \%$ for RSV patients, respectively; both $p<0.0001)$. In association with this, fever, and also febrile convulsions were significantly more often found in FLU patients (Table 1). Acute otitis media was significantly more often diagnosed among FLU patients $(p<0.0001)$.

RSV patients needed significantly more often oxygen therapy $(66 \%$ vs. $24.2 \% ; p<0.0001)$ and salbutamol (68.3\% vs. $27.1 \% ; p<0.0001)$ than FLU patients, and had longer hospital stays (5 vs. 4 days; $p=0.0023$ ), while there were no statistically significant differences concerning the need for intensive care and antibiotic therapy. One FLU patient died due to severe pneumonia with suspected bacterial co-infection, leading to respiratory failure.

\section{Laboratory, microbiological and radiological findings in RSV and FLU patients}

No significant differences were found between both groups concerning C-reactive protein (CRP) and white blood cell counts (WBC). Chest radiographs were performed slightly more often in RSV patients $(28.4 \%$ vs. $19.8 \%$; not significant), while infiltrates were slightly more frequently diagnosed among FLU patients $(72.2 \%$ vs. 53.3\%; not significant).

For 19 patients, a multiplex PCR on a nasopharyngeal swab was available (14 RSV patients, 5 FLU patients). Among the 14 patients with RSV infection for whom a multiplex PCR was available, adenovirus was concomitantly detected in two patients and coronavirus and Bordetella pertussis in one patient, each. In FLU patients, adenovirus and human metapneumovirus were detected in one patient, each. Blood cultures were ordered in 165 patients with RSV, of whom 9 were positive, all of which were deemed contaminants (5 coagulase negative staphylococci; 1 co-detection of Staphylococcus epidermidis, Streptococcus mitis, and Streptococcus peroris; 1 codetection of Micrococcus luteus and Pseudomonas stutzeri; 1 Micrococcus luteus; 1 Rothia dentocariosa). For FLU patients, blood cultures were ordered in 54, with 3 positive cultures, all regarded as contamination (2 Staphylococcus hominis; 1 Corynebacterium afermentans).

\section{Antibiotic utilization}

Antibiotics were prescribed in 136/476 (28.6\%) of RSV patients and 21/95 (22.1\%) of FLU patients $(p=0.2107)$. A monotherapy was used in $77 / 136$ (56.6\%) in RSV patients and 15/21 (71.4\%) of FLU patients $(p=0.2395)$, while the remaining fractions were prescribed a combination therapy. For RSV patients, the most frequently ordered therapies were aminopenicillin monotherapy in 44/136 (32.4\%), ampicillin + flucloxacillin combination therapy in 41/136 (30.1\%), and ampicillin + gentamicin combination therapy in $17 / 136$ (12.5\%). For FLU patients, ampicillin/sulbactam was prescribed in $7 / 21$ (33.3\%), followed by an aminopenicillin monotherapy in $4 / 21(19.0 \%)$ and ampicillin + flucloxacillin combination therapy in 4/21 (19.0\%). The distribution of prescribed antibiotics is depicted in Fig. 2. The median length of antibiotic therapy was 5.5 days for RSV patients (IQR 4$7)$ and 6 days for FLU patients (IQR $4-8)(p=0.3680)$. 
A

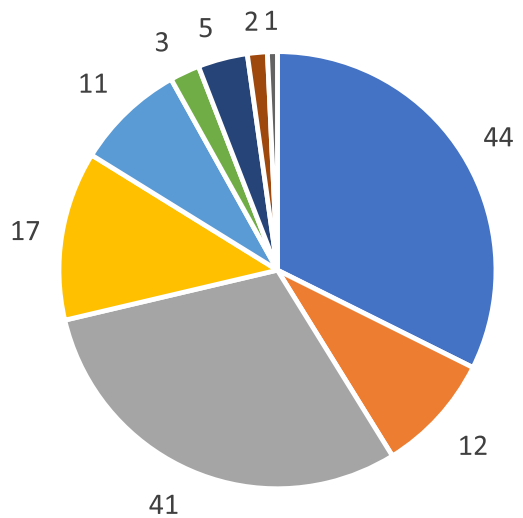

- Ampicillin/Amoxicillin

- Ampicillin/Sulbactam

- Ampicillin+Flucloxacillin

- Ampicillin+Gentamicin

- Cefuroxim

- 3rd/4th gen. Cephalosporin

- Clarithromycin

- Cefaclor

- Meropenem+Vancomycin

B

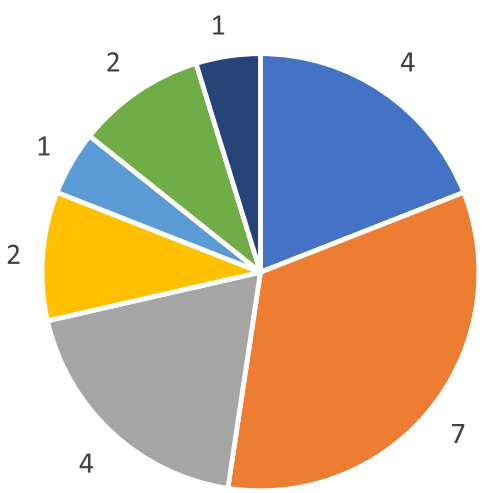

- Ampicillin/Amoxicillin

- Ampicillin/Sulbactam

- Ampicillin+Flucloxacillin

- Ampicillin+Gentamicin

- Cefuroxim

- 3rd/4th gen. Cephalosporin

- Penicillin

Fig. 2 Distribution of empiric antibiotics prescribed after hospitalization, absolute numbers; a RSV patients $(N=136)$; $\mathbf{b}$ influenza patients ( $N=21)$; gen.: generation

\section{Subgroup comparison - RSV patients}

We compared RSV patients who received antibiotics (RSV+AB+) during the hospital stay to those without antibiotics (RSV+AB-). Children who were $\mathrm{RSV}+\mathrm{AB}+$ were significantly older than RSV+AB- (6 vs. 3 months; $p=$ 0.0025) (Table 2). Furthermore, they presented significantly more often with fever $(91.2 \%$ vs. $60.6 \%$; $p<$ $0.0001)$, a septic appearance ( $48.5 \%$ vs. $30 \% ; p=0.0002)$, pneumonia $(76.8 \%$ vs. $39.1 \% ; p<0.0001)$, acute otitis media $(26.5 \%$ vs. $10 \% ; p<0.0001)$, and a higher CRP on admission $(26.9 \mathrm{mg} / \mathrm{L}$ vs. $4.3 \mathrm{mg} / \mathrm{L} ; p<0.0001)$. During the hospital stay, RSV $+\mathrm{AB}+$ children had significantly higher rates of chest radiographies $(60.3 \%$ vs. $15.6 \% ; p<$ $0.0001)$, blood cultures obtained $(52.2 \%$ vs. $27.6 \% ; p<$ $0.0001)$, oxygen therapy $(80.1 \%$ vs. $60 \% ; p<0.0001)$, intensive care stays $(9.6 \%$ vs. $0.9 \% ; p<0.0001)$, and longer hospital stays in total ( 6 days vs. 5 days; $p<0.0001$ ).

\section{Subgroup comparison - FLU patients}

For FLU patients, a significant difference upon clinical presentation was a higher rate of pneumonia $(52.4 \%$ vs.
$13.5 \% ; p=0.0005)$ and acute otitis media $(57.1 \%$ vs. 28.4\%; $p=0.0199$ ) among children receiving antibiotics (FLU $+\mathrm{AB}+$ ) compared to children without antibiotics (FLU+AB-) (Table 2). Apart from that, FLU+AB+ children had significantly higher CRP on admission (23.1 $\mathrm{mg} / \mathrm{L}$ vs. $4.9 \mathrm{mg} / \mathrm{L} ; p<0.0001)$ and peak CRP $(54.9 \mathrm{mg} / \mathrm{L}$ vs. $9.4 \mathrm{mg} / \mathrm{L} ; p<0.0001)$ in the course of disease; a higher rate of chest radiography performed $(52.4 \%$ vs. 9.5\%; $p<0.0001)$, higher need for oxygen therapy $(57.1 \%$ vs. $14.9 \% ; p=0.0002$ ), and a longer hospital stay ( 6 days vs. 5 days; $p=0.0003$ ).

\section{Risk factors for antibiotic use}

We performed a multivariate logistic regression to identify risk factors associated with antibiotic utilization among both RSV and FLU. The best model fit for antibiotic use at any time point was achieved for the following factors (c-index 0.916) (Table 3): otitis media (odds ratio 8.33 ; 95\% confidence interval 3.58-19.37), peak CRP (OR 1.77; 95\% CI 1.54-2.04), and the length of oxygen therapy (OR 1.40; 95\% CI 1.13-1.74). Septic 
Table 2 Comparison of clincial and laboratory characteristics of RSV and FLU patients receiving antibiotics (AB+) to those not receiving antibiotics (AB-); median and interquartile range are indicated for continuous variables

\begin{tabular}{|c|c|c|c|c|c|c|}
\hline Variables & $\begin{array}{l}\text { RSV } \\
\mathrm{AB}+\end{array}$ & $\begin{array}{l}\text { RSV } \\
\text { AB- }\end{array}$ & $p$-values & $\begin{array}{l}\text { FLU } \\
A B+\end{array}$ & $\begin{array}{l}\text { FLU } \\
\text { AB- }\end{array}$ & $p$-values \\
\hline N (\%) & 136/476 (28.6\%) & $340 / 476(71.4 \%)$ & & 21/95 (22.1\%) & 74/95 (77.9\%) & \\
\hline Male & 76/136 (55.1\%) & 193/340 (56.8\%) & ns & $11 / 21(52.4 \%)$ & $44 / 74(59.5 \%)$ & ns \\
\hline Age, months & $6(2-12)$ & $3(2-7)$ & 0.0025 & $14(9-18)$ & $11(5-17.8)$ & ns \\
\hline Duration of illness, days & $4(2-5)$ & $3(2-5)$ & ns & $3(2-5.3)$ & $2(2-4)$ & ns \\
\hline Fever $\left(\geq 38.0^{\circ} \mathrm{C}\right)$ & 124/136 (91.2\%) & 206/340 (60.6\%) & $<0.0001$ & 20/21 (95.2\%) & 73/74 (98.6\%) & ns \\
\hline Body temperature on admission, ${ }^{\circ} \mathrm{C}$ & $38.0(37.4-38.8)$ & $37.4(37.0-38.1)$ & $<0.0001$ & $38.2(37.7-39-4)$ & $38.4(37.4-39.3)$ & ns \\
\hline Peak body temperature, ${ }^{\circ} \mathrm{C}$ & $39.2(38.8-39.8)$ & $38.2(37.5-39.2)$ & $<0.0001$ & $40.0(39.4-40.1)$ & $39.8(39.1-40.0)$ & ns \\
\hline Oxygen saturation at admission, \% & $96(93-98)$ & $97(95-98)$ & 0.0019 & $97(93.3-98.3)$ & $98(97-100)$ & ns \\
\hline Minimal oxygen saturation, \% & $89(88-92)$ & $91(88-95)$ & $<0.0001$ & $90(87.8-95.3)$ & $96(95-98)$ & ns \\
\hline Need for intensive care & 13/136 (9.6\%) & 3/340 (0.9\%) & $<0.0001$ & $1 / 21(4.8 \%)$ & $0 / 74$ & ns \\
\hline Length of stay, days & $6(5-8.3)$ & $5(3-7)$ & $<0.0001$ & $6(5-8.5)$ & $5(3-7)$ & 0.0003 \\
\hline Blood culture obtained & $71 / 136(52.2 \%)$ & $94 / 340(27.6 \%)$ & $<0.0001$ & 12/21 (57.1\%) & $42 / 74(56.8 \%)$ & ns \\
\hline CRP on admission, mg/L & $26.9(9.7-51.2)$ & $4.3(0-10.6)$ & $<0.0001$ & $23.1(5.9-58.4)$ & $4.9(0-13.0)$ & $<0.0001$ \\
\hline Peak CRP, mg/L & $40.5(19.2-61.5)$ & $7.9(4.5-14.4)$ & $<0.0001$ & $54.9(11.7-76.8)$ & $9.4(4.2-14.2)$ & $<0.0001$ \\
\hline WBC on admission, $10^{9} / \mathrm{L}$ & $11.6(8.5-15.2)$ & $10.5(8.5-12.7)$ & ns & $9.9(7.6-12.0)$ & $10.9(7.1-13.7)$ & ns \\
\hline Chest radiography performed & $82 / 136(60.3 \%)$ & $53 / 340(15.6 \%)$ & $<0.0001$ & $11 / 21(52.4 \%)$ & 7/74 (9.5\%) & $<0.0001$ \\
\hline Infiltrate on chest radiogram & 48/82 (58.5\%) & 24/53 (45.3\%) & ns & 8/11 (72.7\%) & 5/7 (71.4\%) & ns \\
\hline Preexisting antibiotic therapy & 19/136 (14.0\%) & 13/340 (3.8\%) & 0.0002 & 6/21 (13.7\%) & 8/74 (3.9\%) & ns \\
\hline Well appearance & $1 / 136(0.7 \%)$ & $31 / 340(9.1 \%)$ & 0.0004 & 2/21 (9.5\%) & 4/74 (5.4\%) & ns \\
\hline III appearance & 60/136 (44.1\%) & $185 / 340(54.4 \%)$ & 0.0536 & $12 / 21(57.1 \%)$ & $50 / 74(67.6 \%)$ & ns \\
\hline Septic appearance & $66 / 136(48.5 \%)$ & $102 / 340(30 \%)$ & 0.0002 & 6/21 (28.6\%) & 17/74 (23.0\%) & ns \\
\hline Acute otitis media & $36 / 136(26.5 \%)$ & $34 / 340(10 \%)$ & $<0.0001$ & 12/21 (57.1\%) & 21/74 (28.4\%) & 0.0199 \\
\hline Upper respiratory tract infection & 0/136 (0\%) & 0/340 (0\%) & ns & $5 / 21(23.8 \%)$ & $42 / 74(56.8 \%)$ & 0.0123 \\
\hline Bronchitis/Bronchiolitis & $31 / 136(22.5 \%)$ & 207/340 (60.9\%) & $<0.0001$ & $1 / 21(4.8 \%)$ & $5 / 74(6.8 \%)$ & ns \\
\hline Pneumonia & 106/136 (76.8\%) & 133/340 (39.1\%) & $<0.0001$ & $11 / 21(52.4 \%)$ & 10/74 (13.5\%) & 0.0005 \\
\hline Fever of unknown origin & 0/136 (0\%) & 0/340 (0\%) & ns & 4/21 (19.0\%) & 17/74 (23.0\%) & ns \\
\hline Oxygen therapy & 109/136 (80.1\%) & $204 / 340(60 \%)$ & $<0.0001$ & $12 / 21(57.1 \%)$ & 11/74 (14.9\%) & 0.0002 \\
\hline Length of oxygen therapy, days & $3(2-6)$ & $2(0-4)$ & $<0.0001$ & $1(0-6)$ & 0 & 0.0002 \\
\hline
\end{tabular}

appearance (OR 4.882; 95\% CI 0.866-27.505; $p=0.0723$ ) was statistically not significant.

The best model fit for antibiotic use on admission (cindex 0.896) (Table 4) was achieved for otitis media (OR 4.5, 95\% CI 2.1-9.4), CRP on admission (OR 1.7, 95\% CI 1.5-2.0), and septic appearance (OR 8.95, 95\% CI 1.554.1). Pneumonia as a potential risk factor (OR 3.629, 95\% CI 0.902-14.602) missed statistical significance.

\section{Discussion}

In this large retrospective four-season-analysis we present data on more than 570 children below the age of 2 years with RSV or FLU infection, demonstrating a high antibiotic use in a substantial proportion of children.

Recent systematic reviews with meta-analyses had shown that viral testing, including FLU and RSV, does not affect antibiotic prescription rates [17, 18],

Table 3 Logistic regression model for antibiotic use at any time point

\begin{tabular}{llll}
\hline Variables & Odds ratio & $95 \%$ confidence interval & $p$-value \\
\hline Otitis media & 8.325 & $3.577-19.374$ & $<0.0001$ \\
Peak CRP & 1.772 & $1.538-2.041$ & $<0.0001$ \\
Length of oxygen therapy & 1.404 & $1.130-1.744$ & 0.0022 \\
Septic appearance & 4.882 & $0.866-27.505$ & 0.0723 \\
\hline
\end{tabular}


Table 4 Logistic regression model for antibiotic use on admission

\begin{tabular}{llll}
\hline Variable & Odds ratio & $95 \%$ confidence interval & $p$-value \\
\hline Otitis media & 4.496 & $2.141-9.439$ & $<0.0001$ \\
CRP on admission & 1.687 & $1.457-1.953$ & $<0.0001$ \\
Septic appearance & 8.950 & $1.481-54.087$ & 0.0169 \\
Pneumonia & 3.629 & $0.902-14.602$ & 0.0696 \\
\hline
\end{tabular}

indicating that other factors pertaining to the decision-making of physicians need to be addressed by AMS measures.

Although RSV patients were significantly younger in our cohort, this apparently did not contribute to a higher rate of antibiotic utilization, as RSV children with antibiotics were significantly older than RSV children that did not receive antibiotics. Instead, driving factors for a potential antibiotic overuse were a high CRP, the presence of acute otitis media, septic appearance and the length of oxygen therapy.

FLU patients presented significantly more often with fever, febrile convulsions, acute otitis media, and upper respiratory tract infection or fever of unknown origin, while RSV patients presented significantly more often with a lower oxygen saturation, septic appearance, and lower respiratory tract infection or pneumonia.

We found higher rates of blood cultures obtained from FLU patients than from RSV patients, which in large part can be explained by the higher rate of febrile children in the FLU cohort, while chest radiographies were more frequently performed among those who received antibiotics within both groups. Interestingly, we found rates of chest infiltrates comparable between treated and non-treated patient groups. One possible explanation is that performing a chest radiograph serves as a surrogate for disease severity and hence influences the decision to prescribe antibiotics. In previous studies, it was hypothesized that less specific radiologic findings may have pushed physicians towards antibiotic treatment, even in the absence of infiltrates [19]. Still, it is generally advised against routinely performing chest radiographs in children who present with typical clinical findings of viral bronchiolitis, of which the majority is caused by RSV [20].

Male children were more predominant in both RSV and FLU cohorts, which had been reported similarly in previous studies [21], yet without convincing explanations so far [22]. Of note, the rate of antibiotic use before admission was 2.2 times higher among FLU patients, while during hospitalization, more RSV patients received antibiotics.

The antibiotic utilization in $28.6 \%$ of RSV and $22.1 \%$ of FLU patients respectively is lower than in comparable cohorts published in the recent past [23, 24], which may reflect a stronger reluctance to use antibiotics in children with point-of-care test confirmed viral infections at our hospital.

Complex medical comorbidities, such as chronic lung disease due to prematurity and congenital heart disease, are known risk factors for hospitalization due to RSV infection $[25,26]$. In our cohort, we did not find any difference in these comorbidities between RSV and FLU patients.

The strengths of our study are the study size, allowing for robust statistical analyses, the long inclusion period, accounting for fluctuations of virus seasonality, and the consistency in standard of care during the inclusion period, thereby avoiding unwanted biasing effects.

Certain limitations of the study also merit critical appraisal. First, we obtained data retrospectively, bringing about the usual constraints and biases inherent to the nature of retrospective analyses. As such, we could not assess the effect of vaccination coverage, especially pertaining to influenza, on the study outcomes since these data were not systematically obtained. In Germany, currently no general recommendation for FLU vaccination for children exists, but only for those with chronic medical conditions. Secondly, no reference method was applied with regard to the correctness of antibiotic utilization. The correct judgement whether an antibiotic is warranted or not is hindered by the lack of a reference standard. Several methods exist to account for this, e.g. a panel of expert referees, blinded to each other, reviewing each case and adjudicating on the "correct" etiology, i.e. bacterial, viral, bacterial-viral co-infection, or unknown, as applied in other studies [21, 27]. Third, our cohort lacked an additional systematic viral testing beyond RSV and Influenza for all patients, making it impossible to judge whether other viruses, such as adenovirus, may have played a causative role, especially in cases with higher CRP [28]. Other viruses, albeit rarer, such as the human metapneumovirus, can be equally or even more associated with antibiotic overuse in children, as described by Schreiner and colleagues [29]. An extensive pathogen testing in conjunction with a control group of healthy children may have helped to better appraise the role of other viruses or bacteria, since some microorganisms can be found abundantly also in healthy controls [11], and the co-presence of some pathogens have been reported to correlate with disease severity [30]. Of note, O'Grady and colleagues had found that more than half of children with an acute respiratory infection had a viral-bacterial "co-detection" in nasal swabs, the bacterium in most cases being Haemophilus influenzae [31]. In another study in children with lower respiratory tract infections [32], the most common detected potentially pathogenic colonizers were Haemophilus influenzae (32.1\%), Moraxella catharralis (26.7\%), Staphylococcus 
aureus (17.7\%) and Streptococcus pneumoniae (16.7\%). Nevertheless, detection of bacterial colonizers may not help in the decision to initiate antibiotic therapy. Instead, there is evidence that the utilization of viral pointof-care diagnostics may prevent the usage of antibiotics $[33,34]$. Overall, this fits well into the concept of diagnostic as well as antibiotic stewardship. Fourth, our cohort had a low case fatality rate, which reduces comparability to cohorts from other backgrounds, e.g. from low- and middle-income countries, where mortality may be higher [35]. Finally, the low baseline rate of antibiotic utilization may limit the generalizability of our results to other settings where the culture of prescribing antibiotics especially in infants and young children below the age of 2 years may differ [36] due to a lack of AMS or other reasons.

In light of the imperfection of both clinical features [7] and laboratory parameters such as CRP [37, 38], novel diagnostics measures are needed to better distinguish between viral and bacterial infections and thereby help reducing unwarranted antibiotic therapy. New hostprotein based assays, e.g. combining CRP with Myxovirus resistance protein A [39], but also combinations of CRP and tumor-necrosis-factor related apoptosis inducing ligand and interferon-gamma induced protein 10 , have shown very convincing results in studies [21, $40-42]$, with high diagnostic accuracy and a potential to dampen unnecessary antibiotic use. Transcriptomic signatures have also shown to be very accurate in establishing the true etiology [43, 44], and although cost issues and turnaround times steadily improve [45], practical feasibility and implementation into the clinical workflow are persisting challenges still to be taken.

\section{Conclusions}

In summary, we show that clinical appearance on admission, the presence of otitis media, but also a high CRP and the length of oxygen therapy are the main factors associated with antibiotic use in our cohort of in children below the age of 2 years with RSV or FLU infection. It remains to be proven in prospective studies if AMS interventions aiming at viral testing, e.g. as multiplex $\mathrm{PCR}$, in conjunction with more precise biomarkers or combinations thereof can help to effectively reduce antibiotic treatment in children with RSV infection and Influenza.

\section{Abbreviations}

AB: Antibiotic; AMS: Antimicrobial stewardship; CRP: C-reactive protein; FLU: Influenza virus; FUO: Fever of unknown origin; IQR: Interquartile range; OR: Odds ratio; PCR: Polymerase chain reaction; RSV: Respiratory syncytial virus; RTI: Respiratory tract infection; URTI: Upper respiratory tract infection; WBC: White blood cell count
Declaration of interest

None.

\section{Authors' contributions}

CP and T: conceptualization, data curation, interpretation, writing of the initial draft, review, editing. MW: data curation, interpretation, review, editing. CW: interpretation, review, editing. MK: data curation, interpretation, review, editing. HS: interpretation, review, editing. All authors read and approved the final manuscript.

\section{Funding}

not applicable. Open access funding provided by Projekt DEAL.

\section{Availability of data and materials}

The datasets used and analysed during the current study are available from the corresponding author on reasonable request.

\section{Ethics approval and consent to participate}

This study was approved by the ethics committee of the Medical Faculty Mannheim, Heidelberg University (2018-832R-MA). The need for informed consents was waived due to the retrospective nature of the study.

\section{Consent for publication}

not applicable.

\section{Competing interests}

The authors declare that they have no competing interests.

\section{Author details}

${ }^{1}$ Pediatric Infectious Diseases, Medical Faculty Mannheim, Heidelberg University, Mannheim, Germany. ${ }^{2}$ Center for Infectious Diseases, Institute of Medical Microbiology and Hygiene, Saarland University, Kirrberger Strasse, Building 43, 66421 Homburg, Germany. Institute of Medical Statistics and Biomathematics, Medical Faculty Mannheim, Heidelberg University, Mannheim, Germany.

Received: 20 July 2020 Accepted: 11 August 2020

Published online: 17 August 2020

\section{References}

1. Ozkaya-Parlakay A, Gulhan B, Bedir-Demirdag T, Kanik-Yuksek S. Viral etiology of bronchiolitis among pediatric patients. Pediatr Infect Dis J. 2019; 38(9):e233. https://doi.org/10.1097/inf.0000000000002382 Epub 2019/08/14. PubMed PMID: 31408060.

2. GBD 2017 Lower Respiratory Infections Collaborators. Quantifying risks and interventions that have affected the burden of lower respiratory infections among children younger than 5 years: an analysis for the Global Burden of Disease Study 2017. Lancet Infect Dis. 2020;20(1):60-79. https://doi.org/10. 1016/s1473-3099(19)30410-4 Epub 2019/11/05. PubMed PMID: 31678026.

3. Hodgson D, Atkins KE, Baguelin M, Panovska-Griffiths J, Thorrington D, van Hoek AJ, et al. Estimates for quality of life loss due to Respiratory Syncytial Virus. Influenza Other Respir Viruses. 2020;14(1):19-27. https://doi.org/10. 1111/irv.12686 Epub 2019/10/19. PubMed PMID: 31625688; PubMed Central PMCID: PMCPMC6928035.

4. Chirikov W, Simoes EAF, Kuznik A, Kwon Y, Botteman M. Economic Burden Trajectories in Commercially Insured US Infants with Respiratory Syncytial Virus. J Infect Dis. 2019. https://doi.org/10.1093/infdis/jiz160 Epub 2019/04/ 16. PubMed PMID: 30982895

5. Scholz S, Damm O, Schneider U, Ultsch B, Wichmann O, Greiner W. Epidemiology and cost of seasonal influenza in Germany - a claims data analysis. BMC Public Health. 2019;19(1):1090. https://doi.org/10.1186/s12889019-7458-x Epub 2019/08/15. PubMed PMID: 31409319; PubMed Central PMCID: PMCPMC6693205.

6. Kronman MP, Zhou C, Mangione-Smith R. Bacterial prevalence and antimicrobial prescribing trends for acute respiratory tract infections. Pediatrics. 2014;134(4):e956-65. https://doi.org/10.1542/peds.2014-0605 Epub 2014/09/17. PubMed PMID: 25225144.

7. Van den Bruel A, Haj-Hassan T, Thompson M, Buntinx F, Mant D. Diagnostic value of clinical features at presentation to identify serious infection in children in developed countries: a systematic review. Lancet. 2010; 
375(9717):834-45. https://doi.org/10.1016/s0140-6736(09)62000-6 Epub 2010/02/06. PubMed PMID: 20132979.

8. Craig JC, Williams GJ, Jones M, Codarini M, Macaskill P, Hayen A, et al. The accuracy of clinical symptoms and signs for the diagnosis of serious bacterial infection in young febrile children: prospective cohort study of 15 781 febrile illnesses. BMJ. 2010;340:c1594. https://doi.org/10.1136/bmj.c1594 Epub 2010/04/22. PubMed PMID: 20406860; PubMed Central PMCID: PMCP MC2857748.

9. Kronman MP, Banerjee R, Duchon J, Gerber JS, Green MD, Hersh AL, et al. Expanding existing antimicrobial stewardship programs in pediatrics: what comes next. J Pediatric Infect Dis Soc. 2018;7(3):241-8. https://doi.org/10. 1093/jpids/pix104 Epub 2017/12/22. PubMed PMID: 29267871

10. Fleming-Dutra KE, Hersh AL, Shapiro DJ, Bartoces M, Enns EA, File TM $\mathrm{Jr}$, et al. Prevalence of inappropriate antibiotic prescriptions among US ambulatory care visits, 2010-2011. JAMA. 2016;315(17):1864-73. https:// doi.org/10.1001/jama.2016.4151 Epub 2016/05/04. PubMed PMID: 27139059

11. The Pneumonia Etiology Research for Child Health (PERCH) Study Group. Causes of severe pneumonia requiring hospital admission in children without HIV infection from Africa and Asia: the PERCH multi-country casecontrol study. Lancet. 2019;394(10200):757-79. https://doi.org/10.1016/ s0140-6736(19)30721-4 Epub 2019/07/02. PubMed PMID: 31257127; PubMed Central PMCID: PMCPMC6727070.

12. Arriola CS, Kim L, Langley G, Anderson EJ, Openo K, Martin AM, et al. Estimated burden of community-onset respiratory syncytial virus-associated hospitalizations among children aged $<2$ years in the United States, 201415. J Pediatric Infect Dis Soc. 2019. https://doi.org/10.1093/jpids/piz087 Epub 2019/12/24. PubMed PMID: 31868913

13. Azar MM, Landry ML. Detection of Influenza A and B Viruses and Respiratory Syncytial Virus by Use of Clinical Laboratory Improvement Amendments of 1988 (CLIA)-Waived Point-of-Care Assays: a Paradigm Shift to Molecular Tests. J Clin Microbiol. 2018:56(7). https://doi.org/10.1128/jcm.00367-18 Epub 2018/04/27. PubMed PMID: 29695519; PubMed Central PMCID: PMCP MC6018333.

14. Kitt E, Drew RJ, Cunney R, Beekmann SE, Polgreen P, Butler K, et al. Diagnosis and Management of Pediatric Influenza in the era of rapid diagnostics. J Pediatric Infect Dis Soc. 2020;9(1):51-5. https://doi.org/10. 1093/jpids/piy118 Epub 2018/11/27. PubMed PMID: 30476135.

15. Bonner AB, Monroe KW, Talley LI, Klasner AE, Kimberlin DW. Impact of the rapid diagnosis of influenza on physician decision-making and patient management in the pediatric emergency department: results of a randomized, prospective, controlled trial. Pediatrics. 2003;112(2):363-7 Epub 2003/08/05. PubMed PMID: 12897288.

16. Barlam TF, Cosgrove SE, Abbo LM, MacDougall C, Schuetz AN, Septimus EJ, et al. Implementing an Antibiotic Stewardship Program: Guidelines by the Infectious Diseases Society of America and the Society for Healthcare Epidemiology of America. Clin Infect Dis. 2016;62(10):e51-77. https://doi. org/10.1093/cid/ciw1 18 Epub 2016/04/16. PubMed PMID: 27080992; PubMed Central PMCID: PMCPMC5006285.

17. Vos LM, Bruning AHL, Reitsma JB, Schuurman R, Riezebos-Brilman A, Hoepelman AIM, et al. Rapid molecular tests for influenza, respiratory syncytial virus, and other respiratory viruses: a systematic review of diagnostic accuracy and clinical impact studies. Clin Infect Dis. 2019;69(7): 1243-53. https://doi.org/10.1093/cid/ciz056 Epub 2019/01/29. PubMed PMID: 30689772

18. Lee JJ, Verbakel JY, Goyder CR, Ananthakumar T, Tan PS, Turner PJ, et al. The Clinical Utility of Point-of-Care Tests for Influenza in Ambulatory Care: A Systematic Review and Meta-analysis. Clin Infect Dis. 2019;69(1):24-33. https://doi.org/10.1093/cid/ciy837 Epub 2018/10/05. PubMed PMID: 30285232; PubMed Central PMCID: PMCPMC6579962.

19. Ecochard-Dugelay E, Beliah M, Boisson C, Perreaux F, de Laveaucoupet J, Labrune $P$, et al. Impact of chest radiography for children with lower respiratory tract infection: a propensity score approach. PLoS One. 2014;9(5): e96189. https://doi.org/10.1371/journal.pone.0096189 Epub 2014/05/03. PubMed PMID: 24788944; PubMed Central PMCID: PMCPMC4008561.

20. Carande EJ, Galiza EP, Nickless A, Pollard AJ, Drysdale SB. Viral bronchiolitis management in hospitals in the UK. J Clin Virol. 2018;104:29-33. https://doi. org/10.1016/j.jcv.2018.04.010 Epub 2018/04/29. PubMed PMID: 29704736.

21. van Houten CB, de Groot JAH, Klein A, Srugo I, Chistyakov I, de Waal W, et al. A host-protein based assay to differentiate between bacterial and viral infections in preschool children (OPPORTUNITY): a double-blind, multicentre, validation study. Lancet Infect Dis. 2017;17(4):431-40. https:// doi.org/10.1016/s1473-3099(16)30519-9 Epub 2016/12/26. PubMed PMID: 28012942.

22. Ben-Shmuel A, Sheiner E, Wainstock T, Landau D, Vaknin F, Walfisch A. The association between gender and pediatric respiratory morbidity. Pediatr Pulmonol. 2018:53(9):1225-30. https://doi.org/10.1002/ppul.24083 Epub 2018/06/27. PubMed PMID: 29943901

23. van Houten $C B$, Naaktgeboren C, Buiteman BJM, van der Lee M, Klein A, Srugo I, et al. Antibiotic overuse in children with respiratory syncytial virus lower respiratory tract infection. Pediatr Infect Dis J. 2018;37(11):1077-81. https://doi.org/10.1097/inf.0000000000001981 Epub 2018/03/31. PubMed PMID: 29601448.

24. van Houten CB, Cohen A, Engelhard D, Hays JP, Karlsson R, Moore E, et al. Antibiotic misuse in respiratory tract infections in children and adults-a prospective, multicentre study (TAILORED Treatment). Eur J Clin Microbiol Infect Dis. 2019;38(3):505-14. https://doi.org/10.1007/s10096-018-03454-2 Epub 2019/02/02. PubMed PMID: 30707378; PubMed Central PMCID: PMCP MC6394715.

25. Lim A, Butt ML, Dix J, Elliott L, Paes B. Respiratory syncytial virus (RSV) infection in children with medical complexity. Eur J Clin Microbiol Infect Dis. 2019;38(1):171-6. https://doi.org/10.1007/s10096-018-3409-1 Epub 2018/10/ 31. PubMed PMID: 30374685.

26. Resch B, Puchas C, Resch E, Urlesberger B. Epidemiology of respiratory syncytial virus-related hospitalizations and the influence of viral Coinfections in southern Austria in a 7-year period. Pediatr Infect Dis J. 2020;39(1):12-6. https://doi.org/10.1097/inf.0000000000002494 Epub 2019/10/28. PubMed PMID: 31651808.

27. van Houten $C B$, Naaktgeboren $C A$, Ashkenazi-Hoffnung $L$, Ashkenazi S, Avis W, Chistyakov I, et al. Expert panel diagnosis demonstrated high reproducibility as reference standard in infectious diseases. J Clin Epidemiol. 2019;112:20-7. https://doi.org/10.1016/j.jclinepi.2019.03.010 Epub 2019/04/ 02. PubMed PMID: 30930247.

28. Franz A, Adams O, Willems R, Bonzel L, Neuhausen N, Schweizer-Krantz S, et al. Correlation of viral load of respiratory pathogens and co-infections with disease severity in children hospitalized for lower respiratory tract infection. J Clin Virol. 2010;48(4):239-45. https://doi.org/10.1016/j.jcv.2010.05. 007 Epub 2010/07/22. PubMed PMID: 20646956.

29. Schreiner D, Groendahl B, Puppe W, Off HNT, Poplawska K, Knuf M, et al. High antibiotic prescription rates in hospitalized children with human metapneumovirus infection in comparison to RSV infection emphasize the value of point-of-care diagnostics. Infection. 2019;47(2): 201-7. https://doi.org/10.1007/s15010-018-1194-5 Epub 2018/08/23. PubMed PMID: 30132249

30. Thorburn K, Harigopal S, Reddy V, Taylor N, van Saene HK. High incidence of pulmonary bacterial co-infection in children with severe respiratory syncytial virus (RSV) bronchiolitis. Thorax. 2006;61(7):611-5. https://doi.org/10.1136/ thx.2005.048397 Epub 2006/03/16. PubMed PMID: 16537670; PubMed Central PMCID: PMCPMC2104657 competing interests with regard to the contents of this manuscript.

31. O'Grady KF, Grimwood K, Sloots TP, Whiley DM, Acworth JP, Phillips N, et al. Prevalence, codetection and seasonal distribution of upper airway viruses and bacteria in children with acute respiratory illnesses with cough as a symptom. Clin Microbiol Infect. 2016;22(6):527-34. https://doi.org/10.1016/j. cmi.2016.02.004 Epub 2016/02/27. PubMed PMID: 26916343; PubMed Central PMCID: PMCPMC7128568.

32. Tenenbaum T, Franz A, Neuhausen N, Willems R, Brade J, Schweitzer-Krantz $S$, et al. Clinical characteristics of children with lower respiratory tract infections are dependent on the carriage of specific pathogens in the nasopharynx. Eur J Clin Microbiol Infect Dis. 2012;31(11):3173-82. https://doi. org/10.1007/s10096-012-1682-y Epub 2012/08/02. PubMed PMID: 22850740.

33. Schneider JE, Boehme C, Borisch B, Dittrich S. Application of a simple pointof-care test to reduce UK healthcare costs and adverse events in outpatient acute respiratory infections. J Med Econ. 2020;23(7):673-82. https://doi.org/ 10.1080/13696998.2020.1736872 Epub 2020/04/08. PubMed PMID: 32259465.

34. Cantais A, Mory O, Plat A, Bourmaud A, Giraud A, Costille M, et al. Impact of bedside diagnosis of influenza in the paediatric emergency ward. Clin Microbiol Infect. 2019;25(7):898-903. https://doi.org/10.1016/j.cmi.2018.11. 019 Epub 2018/12/07. PubMed PMID: 30502486.

35. Scheltema NM, Gentile A, Lucion F, Nokes DJ, Munywoki PK, Madhi SA, et al. Global respiratory syncytial virus-associated mortality in young children (RSV GOLD): a retrospective case series. Lancet Glob Health. 2017;5(10):e984-e91. 
https://doi.org/10.1016/s2214-109x(17)30344-3 Epub 2017/09/16. PubMed PMID: 28911764; PubMed Central PMCID: PMCPMC5599304.

36. van de Maat J, van de Voort E, Mintegi S, Gervaix A, Nieboer D, Moll H, et al. Antibiotic prescription for febrile children in European emergency departments: a cross-sectional, observational study. Lancet Infect Dis. 2019; 19(4):382-91. https://doi.org/10.1016/s1473-3099(18)30672-8 Epub 2019/03/ 05. PubMed PMID: 30827808.

37. Van den Bruel A, Thompson MJ, Haj-Hassan T, Stevens R, Moll H, Lakhanpaul $M$, et al. Diagnostic value of laboratory tests in identifying serious infections in febrile children: systematic review. BMJ. 2011;342:d3082. https://doi.org/ 10.1136/bmj.d3082 Epub 2011/06/10. PubMed PMID: 21653621.

38. Brown JVE, Meader N, Wright K, Cleminson J, McGuire W. Assessment of CReactive Protein Diagnostic Test Accuracy for Late-Onset Infection in Newborn Infants: A Systematic Review and Meta-analysis. JAMA Pediatr. 2020. https://doi.org/10.1001/jamapediatrics.2019.5669 Epub 2020/02/06. PubMed PMID: 32011640.

39. Self WH, Rosen J, Sharp SC, Filbin MR, Hou PC, Parekh AD, et al. Diagnostic Accuracy of FebriDx: A Rapid Test to Detect Immune Responses to Viral and Bacterial Upper Respiratory Infections. J Clin Med. 2017;6(10). https://doi.org/ 10.3390/jcm6100094 Epub 2017/10/11. PubMed PMID: 28991170; PubMed Central PMCID: PMCPMC5664009.

40. Oved K, Cohen A, Boico O, Navon R, Friedman T, Etshtein L, et al. A novel host-proteome signature for distinguishing between acute bacterial and viral infections. PLoS One. 2015;10(3):e0120012. https://doi.org/10.1371/ journal.pone.0120012 Epub 2015/03/19. PubMed PMID: 25785720; PubMed Central PMCID: PMCPMC4364938.

41. Srugo I, Klein A, Stein M, Golan-Shany O, Kerem N, Chistyakov I, et al. Validation of a Novel Assay to Distinguish Bacterial and Viral Infections. Pediatrics. 2017;140(4). https://doi.org/10.1542/peds.2016-3453 Epub 2017/ 09/15. PubMed PMID: 28904072.

42. Ashkenazi-Hoffnung L, Oved K, Navon R, Friedman T, Boico O, Paz M, et al. A host-protein signature is superior to other biomarkers for differentiating between bacterial and viral disease in patients with respiratory infection and fever without source: a prospective observational study. Eur I Clin Microbiol Infect Dis. 2018;37(7):1361-71. https://doi.org/10.1007/s10096-0183261-3 Epub 2018/04/28. PubMed PMID: 29700762; PubMed Central PMCID: PMCPMC6015097.

43. Mahajan P, Kuppermann N, Mejias A, Suarez N, Chaussabel D, Casper TC, et al. Association of RNA Biosignatures With Bacterial Infections in Febrile Infants Aged 60 Days or Younger. JAMA. 2016;316(8):846-57. https://doi.org/ 10.1001/jama.2016.9207 Epub 2016/08/24. PubMed PMID: 27552618; PubMed Central PMCID: PMCPMC5122927.

44. Herberg JA, Kaforou M, Wright VJ, Shailes H, Eleftherohorinou H, Hoggart CJ, et al. Diagnostic Test Accuracy of a 2-Transcript Host RNA Signature for Discriminating Bacterial vs Viral Infection in Febrile Children. JAMA. 2016; 316(8):835-45. https://doi.org/10.1001/jama.2016.11236 Epub 2016/08/24 PubMed PMID: 27552617; PubMed Central PMCID: PMCPMC5997174.

45. Gomez-Carballa A, Cebey-Lopez M, Pardo-Seco J, Barral-Arca R, Rivero-Calle I, Pischedda S, et al. A qPCR expression assay of IFI44L gene differentiates viral from bacterial infections in febrile children. Sci Rep. 2019:9(1):11780 https://doi.org/10.1038/s41598-019-48162-9 Epub 2019/08/15. PubMed PMID: 31409879; PubMed Central PMCID: PMCPMC6692396.

\section{Publisher's Note}

Springer Nature remains neutral with regard to jurisdictional claims in published maps and institutional affiliations.

Ready to submit your research? Choose BMC and benefit from:
- fast, convenient online submission
- thorough peer review by experienced researchers in your field
- rapid publication on acceptance
- support for research data, including large and complex data types
- gold Open Access which fosters wider collaboration and increased citations
- maximum visibility for your research: over 100M website views per year
At BMC, research is always in progress.
Learn more biomedcentral.com/submissions

